\title{
Control of mesoporous silica nanostructures and pore- architectures using a thickener and a gelator
}

\author{
Yonggang Yang, Masahiro Suzuki, Sanae Owa, Hirofusa Shirai and Kenji Hanabusa*
}

Department of Functional Polymer Science, Faculty of Textile Science and Technology, Shinshu University, Ueda 386-8567, Japan.

E-mail: hanaken@giptc.shinshu-u.ac.jp

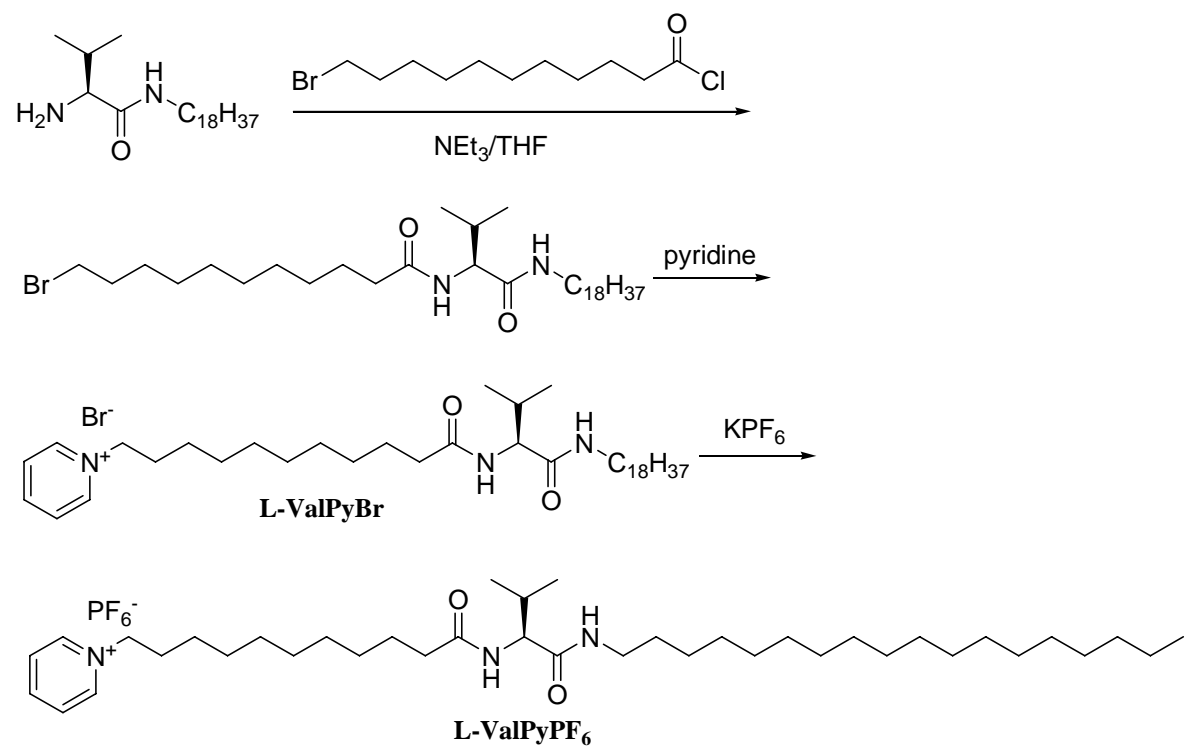

Scheme S1. Syntheses of compounds L-ValPyBr and L-ValPyPF 6 .

\section{Experimental Section}

Characterization TEM images were obtained using a JEOL JEM-2010. FESEM images were taken on a Hitachi S-5000. ${ }^{1} \mathrm{H}-\mathrm{NMR}$ spectra were recorded with a Bruker AVANCE 400 spectrometer using TMS as an internal standard. Elemental analyses were performed on a Perkin Elmer series II CHNS/O analyzer 2400.

Synthesis of L-ValPyBr. Compound $\mathbf{1}$ and $\mathbf{2}$ were prepared according to the previous method (Suzuki, M.; Owa, S.; Kimura, M.; Kurose, A.; Shirai H.; Hanabusa, K. Tetrahedron Lett., 2005, 46, 303). Compound $2(3.50 \mathrm{~g}, 5.68 \mathrm{mmol})$ was heated in $30 \mathrm{~mL}$ of pyridine at $90^{\circ} \mathrm{C}$ overnight under a nitrogen atmosphere. After evaporating pyridine, the recrystallization from a mixture of methanol and diethyl ether gave L-ValPyBr in a yield of $3.47 \mathrm{~g}(88.0 \%)$. ${ }^{1} \mathrm{H}-\mathrm{NMR}\left(400 \mathrm{MHz}, \mathrm{DMSO}-\mathrm{d}_{6}, \mathrm{TMS}, 25^{\circ} \mathrm{C}\right): \delta$ $=0.80-0.87\left(\mathrm{~m}, 9 \mathrm{H} ; \underline{\mathrm{CH}}_{3}\right), 1.23-1.26\left(\mathrm{~m}, 42 \mathrm{H}\right.$; alkyl), $1.36\left(\mathrm{t}, 2 \mathrm{H}, \underline{\mathrm{C}}_{2} \mathrm{CH}_{3}\right), 1.46\left(\mathrm{t}, 2 \mathrm{H}, \mathrm{C}_{2} \mathrm{CH}_{2} \mathrm{CONH}\right)$, 1.85-1.92 (m, 3H; $\mathrm{CONHCH}_{2} \mathrm{CH}_{2}, \mathrm{CH}_{3} \mathrm{C} \underline{H}\left(\mathrm{CH}_{3} \mathrm{CH}_{2}\right)$ ), 2.06-2.19 (m, 2H; $\left.\underline{\mathrm{H}}_{2} \mathrm{CONH}\right), 2.94-3.11$ (m, $\left.2 \mathrm{H} ; \mathrm{CONHC}_{2}\right), 4.08(\mathrm{t}, \mathrm{J}=8.8 \mathrm{~Hz}, 1 \mathrm{H} ; \mathrm{NHC} \underline{\mathrm{HCO}}), 4.59$ (t, J = 7.3 Hz, 2H; $\left.\underline{\mathrm{H}}_{2} \mathrm{Py}\right), 7.71(\mathrm{~d}, \mathrm{~J}=8.8$ $\mathrm{Hz}, 1 \mathrm{H} ; \mathrm{CON} \underline{H C H}), 7.85$ (t, J = 5.6 Hz, 1H; $\left.\mathrm{CON}^{H} \mathrm{CH}_{2}\right), 8.16(\mathrm{t}, \mathrm{J}=7.6 \mathrm{~Hz}, 2 \mathrm{H} ; 3-\mathrm{Py} \underline{H}), 8.60$ (t, J = $7.6 \mathrm{~Hz}, 1 \mathrm{H} ; 4-\mathrm{Py} \underline{H}$ ), 9.10 (d, J = 5.6 Hz, 2H; 2-Py$\underline{H}$ ). Elemental analysis: $\mathrm{C}_{39} \mathrm{H}_{72} \mathrm{BrN}_{3} \mathrm{O}_{2}$ (Mw: 694.91), calcd (\%): C, 67.41; H, 10.44; N, 6.05. found: C, 65.97; H, 10.88; N, 5.70.

Synthesis of L-ValPyPF $\mathbf{~}_{6}$. To $50 \mathrm{~mL}$ of saturated potassium hexafluorophosphate aqueous solution, the solution of L-ValPyBr $(4.40 \mathrm{~g}, 6.34 \mathrm{mmol})$ in $400 \mathrm{~mL}$ of $\mathrm{H}_{2} \mathrm{O}$ and $100 \mathrm{~mL}$ of ethanol was added 
under stirring. After the mixture was stirred for $5 \mathrm{~h}$, the precipitate was filtered, washed with distilled water and dried. The crude product was recrystallized from ethanol. Yield $3.98 \mathrm{~g}(83 \%) .{ }^{1} \mathrm{H}-\mathrm{NMR}$ $\left(400 \mathrm{MHz}, \mathrm{DMSO}-\mathrm{d}_{6}, \mathrm{TMS}, 25^{\circ} \mathrm{C}\right): \delta=0.80-0.87\left(\mathrm{~m}, 9 \mathrm{H} ; \mathrm{C}_{3}\right), 1.23-1.26(\mathrm{~m}, 42 \mathrm{H} ;$ alkyl), $1.41(\mathrm{t}, 2 \mathrm{H}$, $\mathrm{C}_{2} \mathrm{CH}_{3}$ ), 1.52 (t, 2H, $\left.\underline{\mathrm{H}}_{2} \mathrm{CH}_{2} \mathrm{CONH}\right), 1.94-1.99$ (m, 3H; $\mathrm{CONHCH}_{2} \mathrm{C}_{2}, \mathrm{CH}_{3} \mathrm{C} \underline{H}\left(\mathrm{CH}_{3} \mathrm{CH}_{2}\right)$ ), 2.122.21 (m, 2H; $\left.\underline{\mathrm{H}}_{2} \mathrm{CONH}\right), 2.99-3.18\left(\mathrm{~m}, 2 \mathrm{H} ; \mathrm{CONHC}_{2}\right), 4.13$ (t, J = 7.6 Hz, 1H; NHC $\left.=7.3 \mathrm{~Hz}, 2 \mathrm{H} ; \underline{\mathrm{C}}_{2} \mathrm{Py}\right), 7.53(\mathrm{~d}, \mathrm{~J}=8.8 \mathrm{~Hz}, 1 \mathrm{H} ; \mathrm{CON} \underline{H C H}), 7.74\left(\mathrm{t}, \mathrm{J}=5.6 \mathrm{~Hz}, 1 \mathrm{H} ; \mathrm{CON}_{H_{C H}}\right), 8.15(\mathrm{t}$, $\mathrm{J}=7.1 \mathrm{~Hz}, 2 \mathrm{H} ; 3-\mathrm{Py} \underline{H}), 8.60$ (t, J = 7.8 Hz,1H; 4-Py $\underline{H}), 9.10$ (d, J = 5.8 Hz, 2H; 2-Py $\underline{H}$ ). Elemental analysis: $\mathrm{C}_{39} \mathrm{H}_{72} \mathrm{~F}_{6} \mathrm{~N}_{3} \mathrm{O}_{2} \mathrm{P}$ (Mw: 759.97), calcd (\%): C, 61.64; H, 9.55; N, 5.53; found: $\mathrm{C}, 61.51$; H, 9.96; $\mathrm{N}, 5.45$.

Synthesis of bola-L-ValPyPF 6 . Dibromo compound containing L-valine $(7.11 \mathrm{~g}, 10 \mathrm{mmol})$ was refluxed in $50 \mathrm{~mL}$ of pyridine overnight under a nitrogen atmosphere. After evaporating pyridine, the recrystallization from a mixture of methanol and ether gave pyridinium dibromide salt in a yield of 8.43 g $(97 \%)$.

To $80 \mathrm{~mL}$ of saturated $\mathrm{KPF}_{6}$ aqueous solution, the above pyridinium dibromide salt $(8.43 \mathrm{~g}, 9.7$ $\mathrm{mmol}$ ) in $50 \mathrm{~mL}$ of ethanol was added under stirring. After $5 \mathrm{~h}$, the precipitate was filtered, washed with distilled water and dried. The crude hexafluorophosphate salt was recrystallized from ethanol-ether. Yield: $93 \%$. ${ }^{1} \mathrm{H}-\mathrm{NMR}:\left(400 \mathrm{MHz}, \mathrm{DMSO}_{-} \mathrm{d}_{6}, \mathrm{TMS}, 25^{\circ} \mathrm{C}\right): \delta=0.79-0.81\left(\mathrm{~m}, 12 \mathrm{H} ; \mathrm{C}_{3}\right), 1.22$ (br, 14H; alkyl), 1.35-1.38 (m, 4H; $\mathrm{NHCOCH}_{2} \mathrm{C}_{2}$ ), 1.50-1.57 (m, 4H; $\mathrm{CONHCH}_{2} \mathrm{C}_{2}$ ), 1.84-1.96 (m, 6H; $\left.\mathrm{PyCH}_{2} \underline{\mathrm{C}}_{2},\left(\mathrm{CH}_{3}\right)_{2} \mathrm{C} \underline{\mathrm{H}}\right), 2.08-2.23\left(\mathrm{~m}, 4 \mathrm{H} ; \mathrm{C}_{2} \mathrm{CONH}\right), 2.91-3.13$ (m, 4H; CONHC$\left.\underline{H}_{2}\right), 4.05-4.10$ (m,

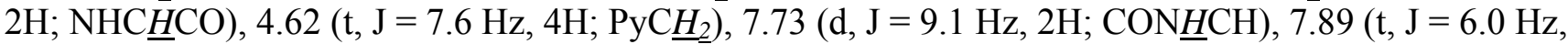

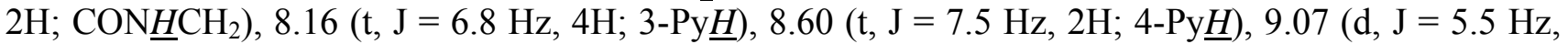
$4 \mathrm{H}$; 2-Py므). Elemental analysis: $\mathrm{C}_{41} \mathrm{H}_{68} \mathrm{~F}_{12} \mathrm{~N}_{6} \mathrm{O}_{4} \mathrm{P}_{2}$ (Mw: 998.94), calcd (\%): C, 49.30; H, 6.86; N, 8.41; found: C, 48.89; $\mathrm{H}, 6.67 ; \mathrm{N}, 8.50$.

Preparation of silica nanostructures in the mixture of 1-propanol and water using $\mathrm{L}-\mathrm{ValPyBr}$ without stirring. L-ValPyBr $(10 \mathrm{mg}, 0.029 \mathrm{mmol})$ was dissolved in the mixture of $0.6 \mathrm{~mL}$ of 1 propanol and $0.4 \mathrm{~mL}$ of $\mathrm{NH}_{3}$ aq. $(10.0 \mathrm{wt} \%)$, and then $20 \mathrm{mg}(0.096 \mathrm{mmol})$ of tetraethoxy orthosilicate (TEOS) was dropped into the solution under strongly stirring at r.t. After having turned to transparent solution, the mixture was kept at $0^{\circ} \mathrm{C}$ for 1 day and $80^{\circ} \mathrm{C}$ for 4 days under static condition. Finally, the template was removed by washing with methanol and calcination was performed in a box furnace in air at $550^{\circ} \mathrm{C}$ for $5 \mathrm{hrs}$, with a ramp rate of $1^{\circ} \mathrm{C} \mathrm{min}^{-1}$.

Preparation of twisted mesoporous silica nanoribbons using L-ValPyBr under stirring. Typical procedure of the sol-gel polycondensation of TEOS was carried out as follows. L-ValPyBr $(10 \mathrm{mg}$, $0.029 \mathrm{mmol}$ ) was dissolved in the mixture of $0.4 \mathrm{~mL}$ of ethanol and $0.6 \mathrm{~mL}$ of $\mathrm{NH}_{3}$ aq. $(10.0 \mathrm{wt} \%)$, and then $20 \mathrm{mg}(0.096 \mathrm{mmol})$ of TEOS was dropped into the solution under strongly stirring at $0^{\circ} \mathrm{C}$. After having turned to white, the mixture was kept at room temperature for 1 day and $80^{\circ} \mathrm{C}$ for 4 days under static condition. Finally, the template was removed by washing with methanol and calcination was performed in a box furnace in air at $550^{\circ} \mathrm{C}$ for $5 \mathrm{hrs}$, with a ramp rate of $1{ }^{\circ} \mathrm{C} \mathrm{min}^{-1}$.

All of the other nanostructures were synthesized under stirring during sol-gel transcription process.

Preparation of twisted mesoporous silica nanoribbons using $\mathrm{L}_{-} \mathrm{ValPyPF}_{6}$ under stirring. Typical procedure of the sol-gel polycondensation of TEOS was carried out as follows. L-ValPyPF $(10 \mathrm{mg}$, $0.013 \mathrm{mmol}$ ) was dissolved in the mixture of $0.6 \mathrm{~mL}$ of ethanol and $0.4 \mathrm{~mL}$ of $10.0 \mathrm{wt} \% \mathrm{NH}_{3}$ aq., then $20 \mathrm{mg}(0.096 \mathrm{mmol})$ of TEOS was dropped into the viscous solution under strongly stirring at room temperature. After having turned to white, stirring was stopped. The gel was kept at room temperature for 1 day and $80^{\circ} \mathrm{C}$ for 4 days under static conditions. Then the gelator was removed by rinsing with 100 $\mathrm{mL}$ of methanol and calcination was performed at $550^{\circ} \mathrm{C}$ for $5 \mathrm{~h}$ in air.

Preparation of 2D/3D mesoporous silica nanoribbons using $\mathrm{L}^{-V a l P y P F_{6}}$ under stirring. LValPyPF $_{6}(40 \mathrm{mg}, 0.053 \mathrm{mmol})$ was dissolved in the mixture of $1.6 \mathrm{~mL}$ of ethanol and $2.4 \mathrm{~mL}$ of 5.0 $\mathrm{wt} \% \mathrm{NH}_{3}$ aq., then $30 \mathrm{mg}(0.144 \mathrm{mmol})$ of TEOS was dropped into the resulting viscous solution under strongly stirring at room temperature. After having turned to white, stirring was stopped. The gel was kept at room temperature for 1 day and $80^{\circ} \mathrm{C}$ for 4 days under static conditions. Then the gelator was removed by rinsing with $100 \mathrm{~mL}$ of methanol and calcination was performed at $550^{\circ} \mathrm{C}$ for $5 \mathrm{~h}$ in air. 
Preparation of silica nanotubes with pores in the wall using bola-L-ValPyPF 6 . Gelator bola-LValPyPF $_{6}(30 \mathrm{mg}, 0.03 \mathrm{mmol})$ was dissolved in $1 \mathrm{~mL}$ of $1.0 \mathrm{M} \mathrm{HCl}$ aq., $50 \mathrm{mg}(0.24 \mathrm{mmol})$ of TEOS was dropped into the solution under strongly stirring at room temperature. After having turned to white, the mixture was kept at room temperature for $30 \mathrm{~min}$. and $80{ }^{\circ} \mathrm{C}$ for 4 days under static conditions. Finally, the gelator was removed by rinsing with methanol and then calcination was performed at $250^{\circ} \mathrm{C}$ for $2 \mathrm{hrs}$ and $500^{\circ} \mathrm{C}$ for $5 \mathrm{hrs}$ in air.

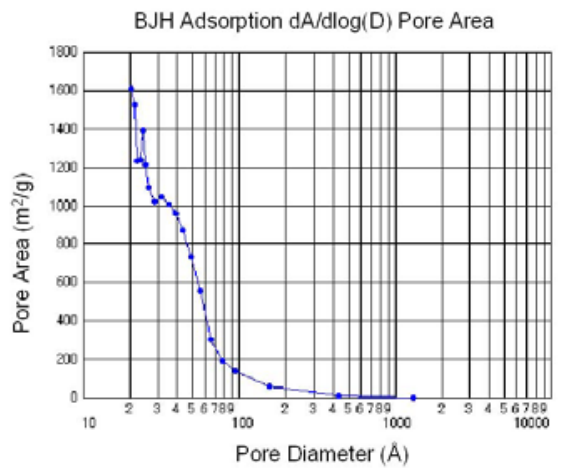

Figure S1. Nitrogen BJH pore size distribution (obtained from the adsorption branch) of the mesoporous silica nanoribbons prepared in the mixture of 2-propanol and water (Sample shown in Fig. 2).

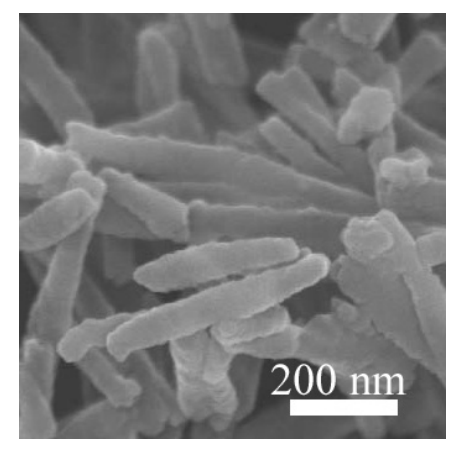

Figure S2. FESEM image of the short rods. Preparation condition: $10 \mathrm{mg}$ of L-ValPyBr, $0.8 \mathrm{~mL}$ of $10.0 \mathrm{wt}-\% \mathrm{NH}_{3}$ aq., $0.2 \mathrm{~mL}$ of 2-propanol, and $20 \mathrm{mg}$ of TEOS.

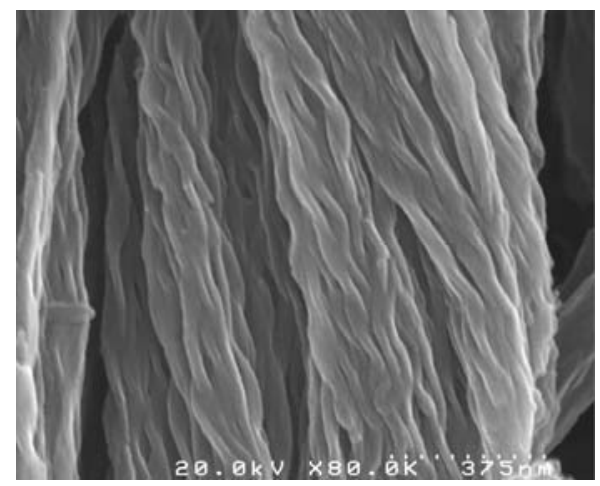

Figure S3. FESEM image of the twisted ribbons. Preparation condition: $10 \mathrm{mg}$ of L-ValPyBr, $0.7 \mathrm{~mL}$ of $10.0 \mathrm{wt}-\% \mathrm{NH}_{3}$ aq., $0.3 \mathrm{~mL}$ of 2-propanol, and $20 \mathrm{mg}$ of TEOS. 


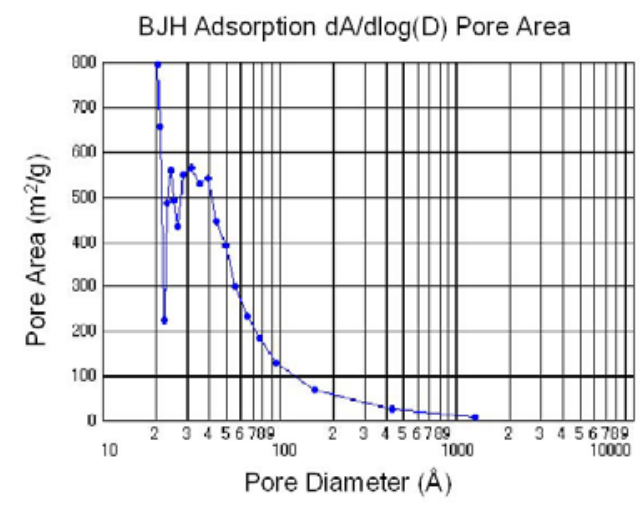

Figure S4. Nitrogen BJH pore size distribution (obtained from the adsorption branch) of the mesoporous silica nanorods prepared in water (Sample shown in Fig. 3).
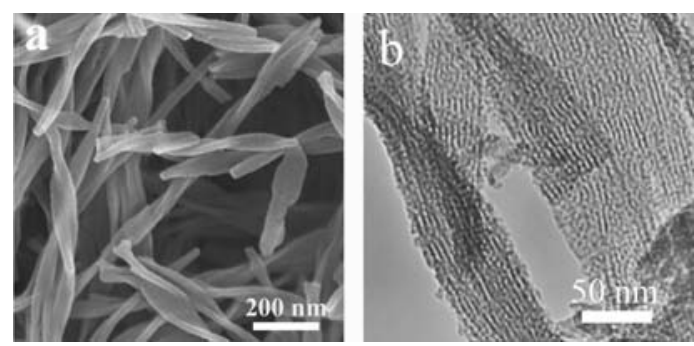

Figure S5. FESEM (a) and TEM (b) images of the twisted mesoporous silica nanoribbons after calcination. Preparation condition: $10 \mathrm{mg}$ of L-ValPyBr, $0.4 \mathrm{ml}$ of ethanol, $0.6 \mathrm{ml}$ of $10.0 \mathrm{wt} \% \mathrm{NH}_{3}$ aq., and $20 \mathrm{mg}$ of TEOS.

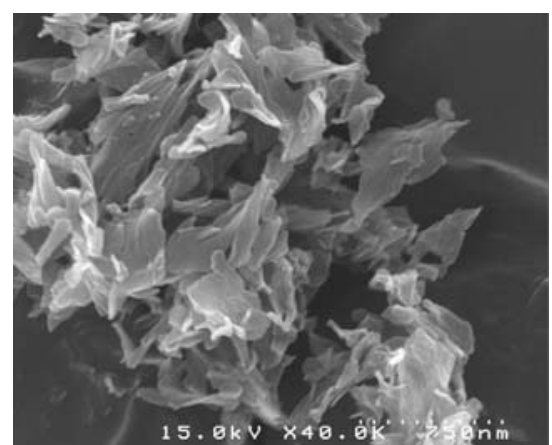

Figure S6. FESEM image of the flakes. Preparation condition: $10 \mathrm{mg}$ of L-ValPyBr, $0.5 \mathrm{~mL}$ of 10.0 $\mathrm{wt} \% \mathrm{NH}_{3}$ aq., $0.5 \mathrm{~mL}$ of ethanol, and $20 \mathrm{mg}$ of TEOS.
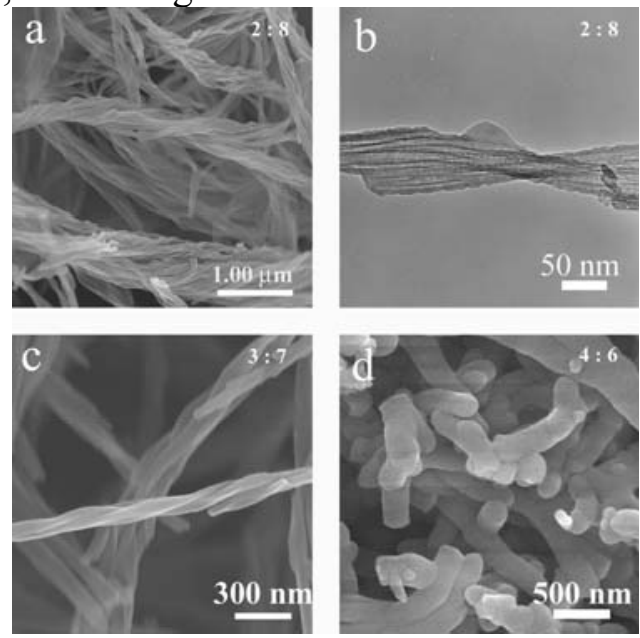
Figure S7. FESEM (a, c, d) and TEM (b) images of mesoporous silica after calcination. Preparation condition for a and b: $10 \mathrm{mg}$ of L-ValPyBr, $0.2 \mathrm{ml}$ of methanol, $0.8 \mathrm{ml}$ of $10.0 \mathrm{wt} \% \mathrm{NH}_{3}$ aq., and $20 \mathrm{mg}$ of TEOS. Preparation condition for c: $10 \mathrm{mg}$ of L-ValPyBr, $0.3 \mathrm{ml}$ of methanol, $0.7 \mathrm{ml}$ of $10.0 \mathrm{wt} \%$ $\mathrm{NH}_{3}$ aq., and $20 \mathrm{mg}$ of TEOS. Preparation condition for d: $10 \mathrm{mg}$ of L-ValPyBr, $0.4 \mathrm{ml}$ of methanol, 0.6 $\mathrm{ml}$ of $10.0 \mathrm{wt} \% \mathrm{NH}_{3}$ aq., and $20 \mathrm{mg}$ of TEOS.

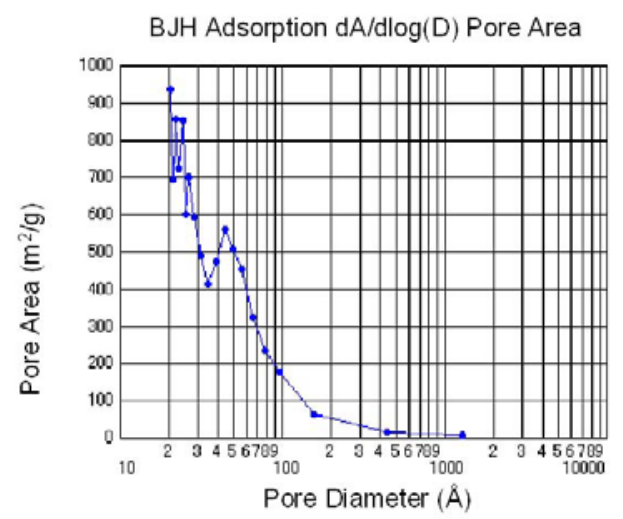

Figure S8. Nitrogen $\mathrm{BJH}$ pore size distribution (obtained from the adsorption branch) of the mesoporous silica nanoribbons prepared in the mixture of methanol and water (Sample shown in Fig. S7a).

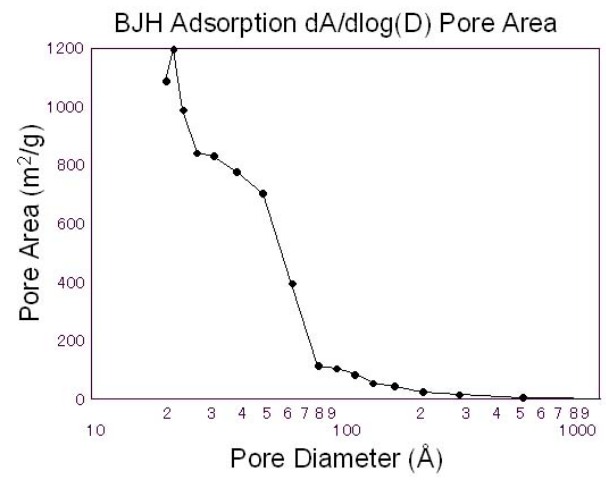

Figure S9. Nitrogen BJH pore size distribution (obtained from the adsorption branch) of the mesoporous silica nanoribbons prepared in the mixture of 1-propanol and water (Sample shown in Fig. 5a).

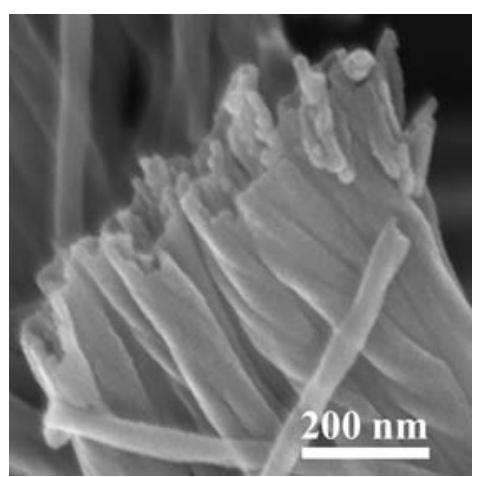

Figure S10. FESEM image of the calcined silica nanotubes under stirring during the synthetic process. Synthesis condition: $10 \mathrm{mg}$ of L-ValPyBr : $0.4 \mathrm{~mL}$ of $10.0 \mathrm{wt}-\% \mathrm{NH}_{3}$ aq.: $0.6 \mathrm{~mL}$ of 1-propanol : $20 \mathrm{mg}$ of TEOS. 


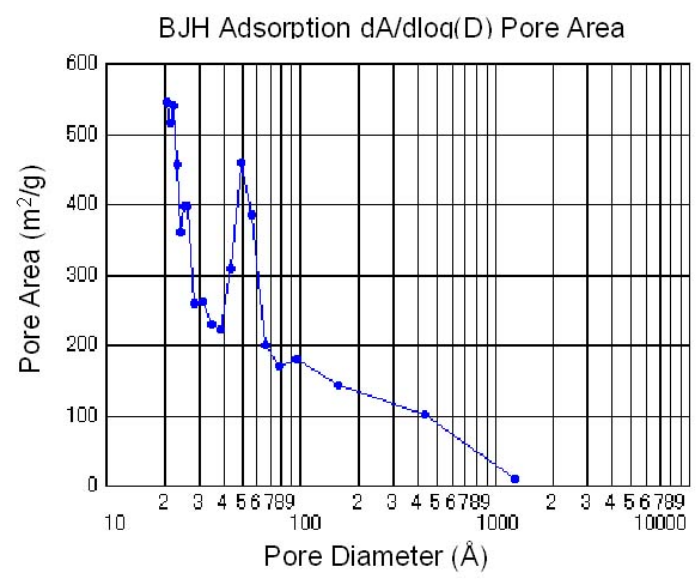

Figure S11. Nitrogen BJH pore size distribution (obtained from the adsorption branch) of the mesoporous silica nanotubes prepared in the mixture of 1-propanol and water (Sample shown in Fig. 5e). BJH Adsorption dA/dlog(D) Pore Area

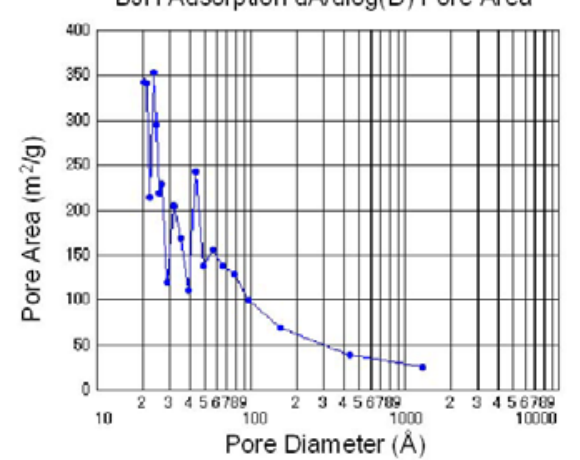

Figure S12. Nitrogen BJH pore size distribution (obtained from the adsorption branch) of the mesoporous silica nanotubes prepared in the mixture of 1-propanol and water (Sample shown in Fig. $5 \mathrm{~g})$.

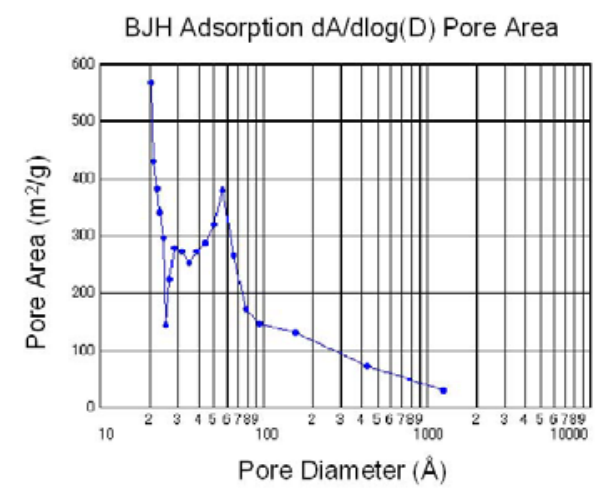

Figure S13. Nitrogen BJH pore size distribution (obtained from the adsorption branch) of the mesoporous silica nanotubes prepared in the mixture of 1-propanol and water (Sample shown in Fig. 6).

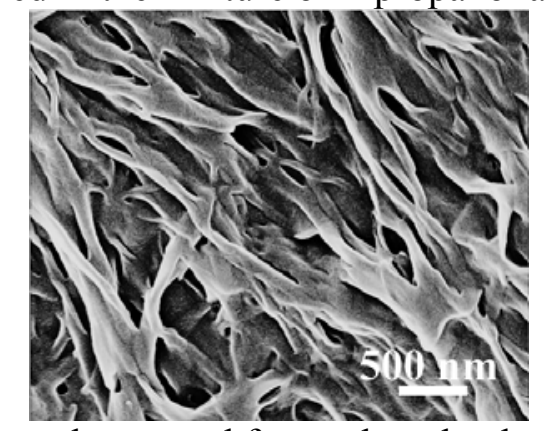

Figure S14. FESEM image of a xerogel prepared from ethanol gel of L-ValPyPF 6 . 


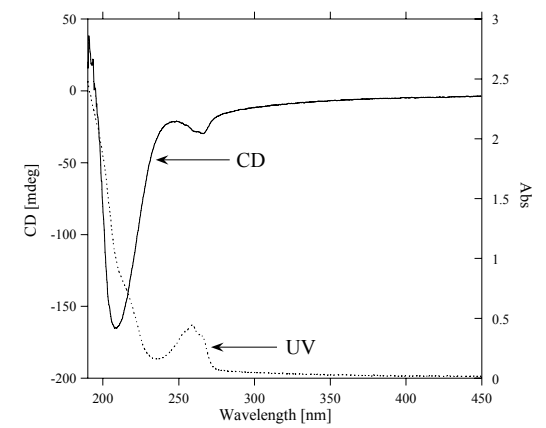

Figure S15. CD and UV spectra of ${ }_{\mathrm{L}}-\mathrm{ValPyPF}_{\mathbf{6}}$ aggregates in water (concentration: $10.0 \mathrm{mg} / 1.0 \mathrm{~mL}$ ).

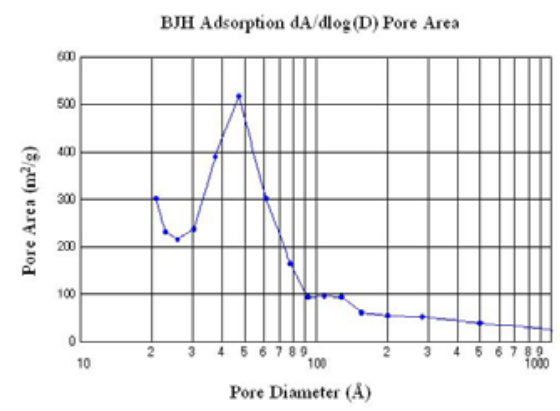

Figure S16. BJH pore size distribution plot determined from adsorption branch (Sample shown in Fig. 8a).
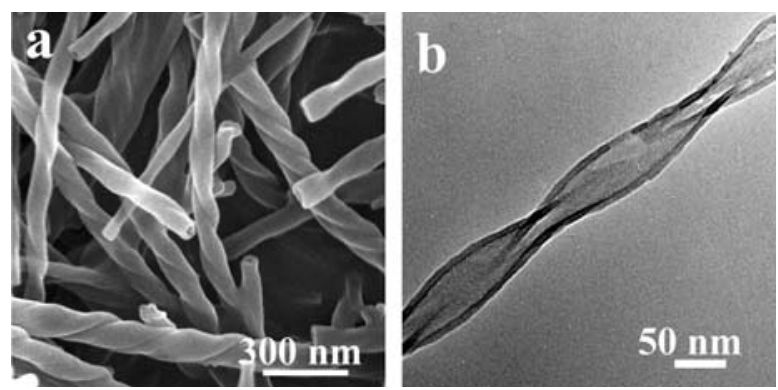

Figure S17. FESEM (a) and TEM (b) images of left-handed helical silica nanotubes. Preparation condition: $10 \mathrm{mg}$ of L-ValPyPF 6 , $1.6 \mathrm{~mL}$ of ethanol, $0.4 \mathrm{~mL}$ of $10.0 \mathrm{wt} \% \mathrm{NH}_{3}$ aq., and $20 \mathrm{mg}$ of TEOS.

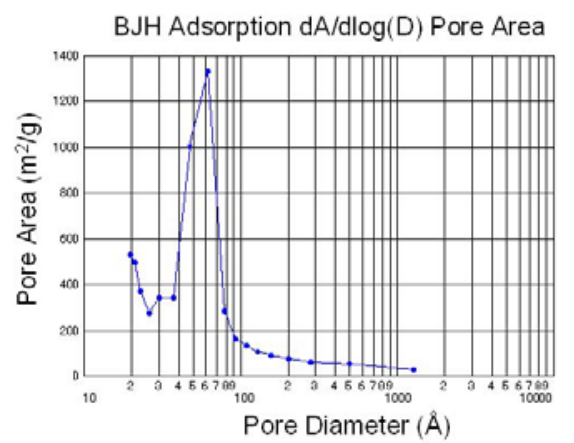

Figure S18. Nitrogen BJH pore size distribution (obtained from the adsorption branch) of the mesoporous silica bundles prepared in the mixture of ethanol and water (Sample shown in Fig. 9a). 


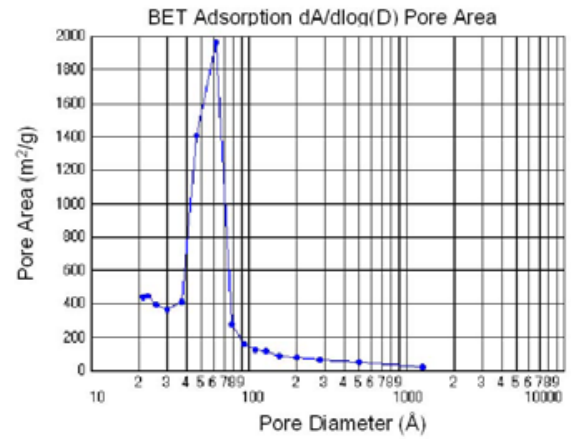

Figure S19. Nitrogen BJH pore size distribution (obtained from the adsorption branch) of the mesoporous silica bundles prepared in the mixture of ethanol and water (Sample shown in Fig. 9b).

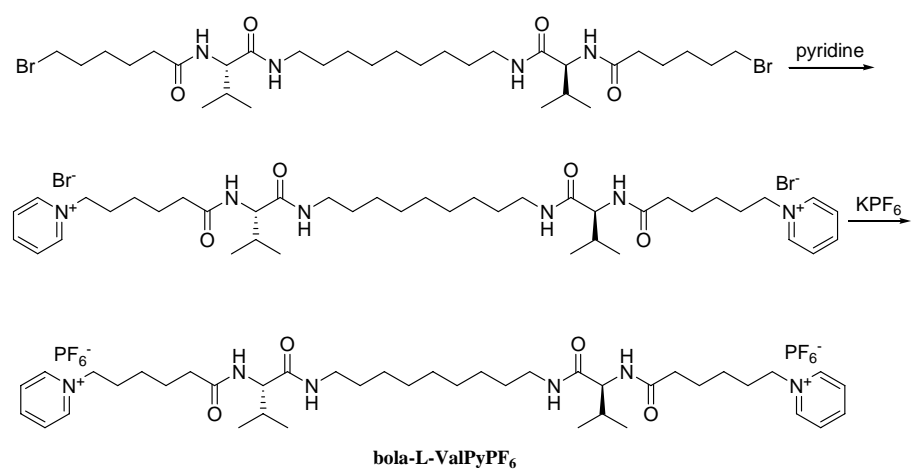

Scheme S2. Synthesis of bola-L-ValPyPF 6.
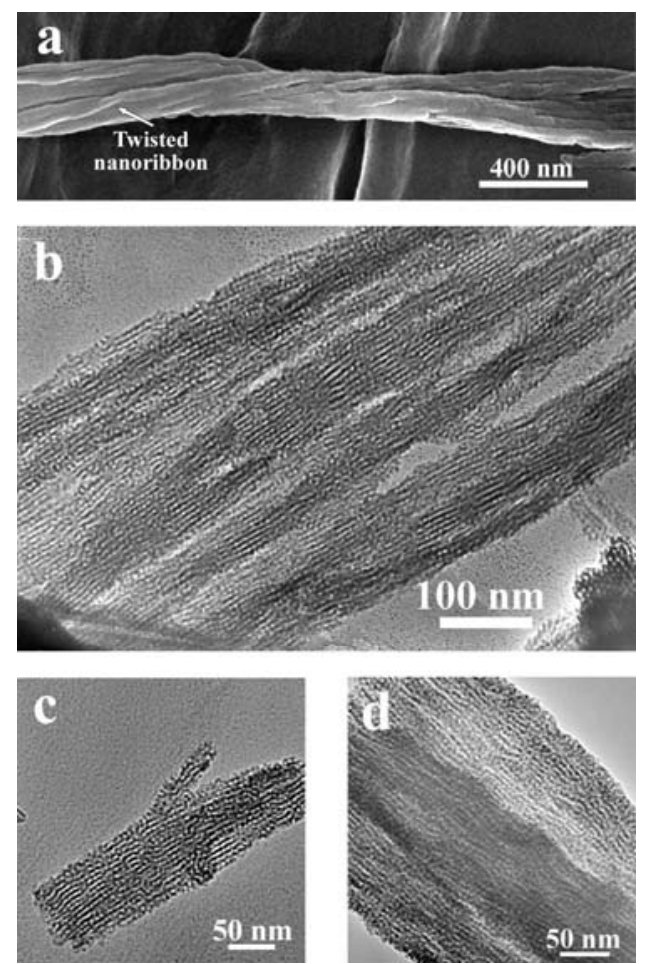

Figure S20. FESEM (a) and TEM (b, c, d) images of silica ribbons. Preparation condition for a, b, and c: $40 \mathrm{mg}$ of $\mathrm{L}-\mathbf{V a l P y P F}_{6}, 1.6 \mathrm{~mL}$ of ethanol, $2.4 \mathrm{~mL}$ of $5.0 \mathrm{wt} \% \mathrm{NH}_{3}$ aq., and $30 \mathrm{mg}$ of TEOS; preparation condition for d: $40 \mathrm{mg}$ of $\mathrm{L}_{-} \mathbf{V a l P y P F}_{6}, 1.6 \mathrm{~mL}$ of ethanol, $2.4 \mathrm{~mL}$ of $5.0 \mathrm{wt} \% \mathrm{NH}_{3}$ aq., and $60 \mathrm{mg}$ of TEOS. 

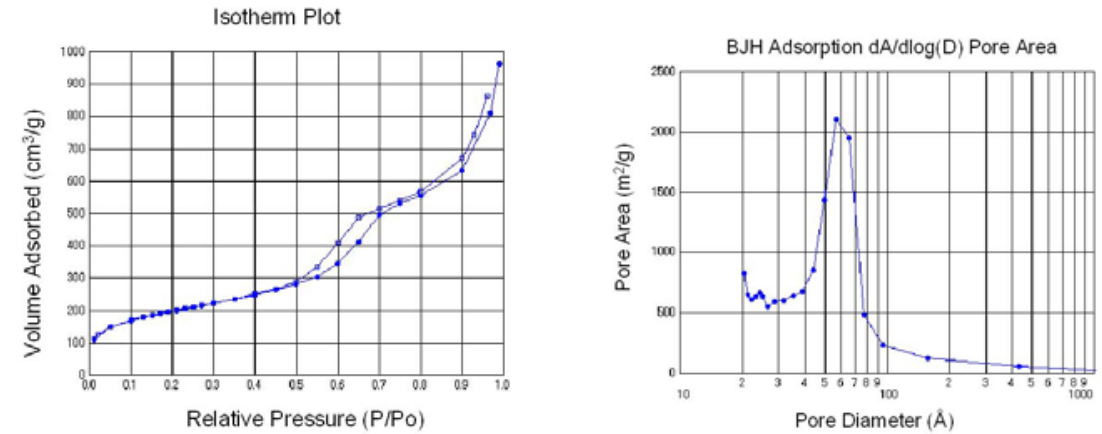

Figure S21. $\mathrm{N}_{2}$ adsorption-desorption isotherms and BJH pore size distribution (obtained from the adsorption branch) of the mesoporous silica bundles prepared in the mixture of ethanol and water using L-ValPyPF 6 (Sample shown in Fig. S20a).
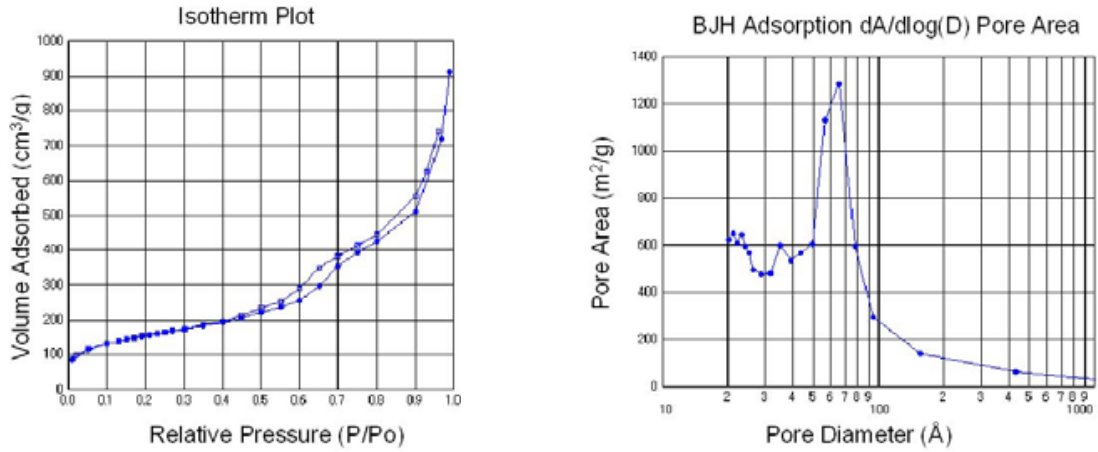

Figure S22. $\mathrm{N}_{2}$ adsorption-desorption isotherms and BJH pore size distribution (obtained from the adsorption branch) of the mesoporous silica bundles prepared in the mixture of ethanol and water using L-ValPyPF 6 (Sample shown in Fig. S20d). 


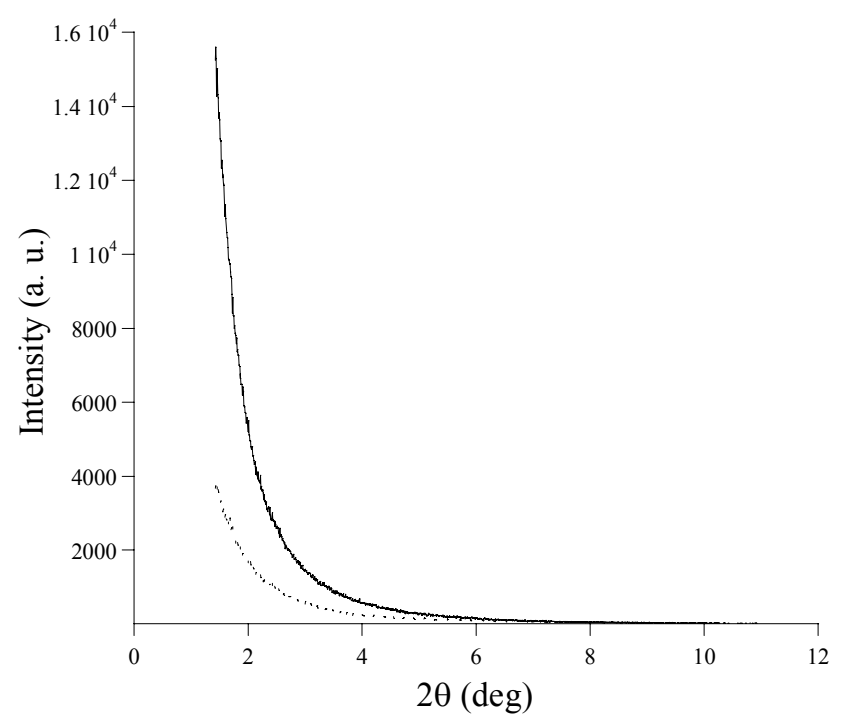

Figure S23. Small angle X-ray diffraction graphs of samples shown in Fig. 3 (real line) and Fig. 5a and $5 \mathrm{~b}$ (dot line).

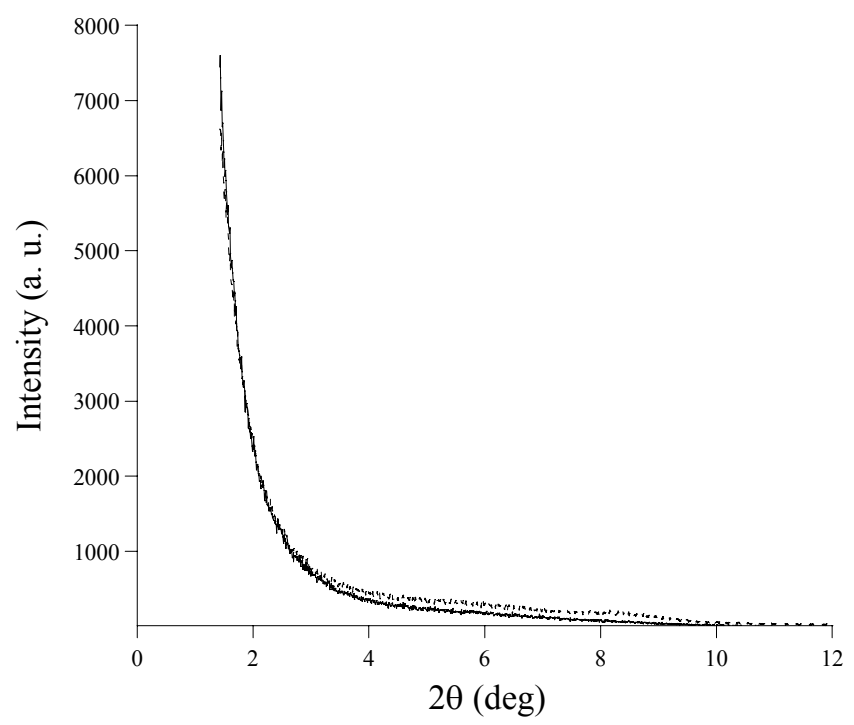

Figure S24. Small angle X-ray diffraction graphs of samples shown in Fig. 7 (real line) and Fig. S20d (dot line). 